\title{
Síndrome de Guillain-Barré como complicação da infecção arboviral da Dengue: revisão de literatura
}

\author{
Guillain-Barré syndrome as a complication of Dengue arboviral infection: literature review \\ Síndrome de Guillain-Barré como complicación de la infección por arbovirus del Dengue: \\ revisión de la literatura
}

Pedro Duarte Moreira Andrade ${ }^{1 *}$, Ana Cláudia Felipe Santiago ${ }^{1}$, Camila Baquieti Carminate ${ }^{1}$, Camilla de Freitas Maziero ${ }^{1}$, Camila Moreira Costa ${ }^{1}$, Daniele Milagres Batista ${ }^{1}$, Isabela Guedes Paiva1, Layandra Vittória de Assis ${ }^{1}$, Paula Moreira Sena ${ }^{1}$, Layara de Assis ${ }^{1}$.

\section{RESUMO}

Objetivo: Correlacionar a infecção pela dengue e o desenvolvimento da Síndrome de Guillain-Barré (SGB). Revisão bibliográfica: Os resultados demonstram que existe uma associação da infecção pela dengue, e o desenvolvimento da SGB, principalmente no verão, período de predominância do vírus. De acordo com a Organização Mundial da Saúde (OMS), a dengue é uma patologia febril associada a dois ou mais dos sintomas: cefaléia, dor retroorbital, mialgia/ artralgia, exantema e petéquias com prova do laço positiva, de início agudo com duração de 2-7 dias. Já a SGB é uma polirradiculoneuropatia inflamatória desmielinizante aguda de caráter autoimune, ou seja, o sistema imunológico reconhece e ataca o sistema nervoso levando à lesão da bainha de mielina. Considerações finais: Portanto, este estudo revelou uma associação entre SGB com essa arbovirose, sendo que a febre é a principal sintomatologia para identificação da infecção pelo arbovírus, seguido de mialgia, artralgia e exantema, bem como paresias e/ou plegias progressivas e ascendentes são fatores determinantes para a identificação da SGB. Dessa maneira, a prevenção contra os vetores é fundamental para diminuir o índice de infecções e consequentemente diminuir os casos de possível desenvolvimento da SGB, melhorando o prognóstico dos pacientes.

Palavras-chave: Síndrome Guillain-Barré, Dengue, Complicação.

\begin{abstract}
Objective: To correlate dengue infection and the development of Guillain-Barré Syndrome (GBS). Bibliographic review: The results demonstrate that there is an association between dengue infection and the development of GBS, especially in the summer, period of predominance of the virus. According to the World Health Organization (WHO), dengue is a febrile pathology associated with two or more of the symptoms: headache, retroorbital pain, myalgia/arthralgia, exanthema and positive loop petechiae, of acute onset lasting 2-7 days. GBS, on the other hand, is an acute demyelinating inflammatory polyradiculoneuropathy of an autoimmune nature, that is, the immune system recognizes and attacks the nervous system, leading to damage to the myelin sheath. Final considerations: Therefore, this study revealed an association between GBS and this arbovirus, with fever being the main symptom for identifying arbovirus infection, followed by myalgia, arthralgia and rash, as well as progressive and ascending paresis and/or plegias. determining factors for the identification of GBS. Thus, prevention against vectors is essential to reduce the rate of infections and, consequently, reduce cases of possible development of GBS, improving the prognosis of patients.
\end{abstract}

Key words: Guillain-Barré syndrome, Dengue, Complications.

\section{RESUMEN}

Objetivo: Correlacionar la infección por dengue y el desarrollo del síndrome de Guillain-Barré (SGB). Revisión bibliográfica: Los resultados demuestran que existe una asociación entre la infección por dengue y el desarrollo de SGB, especialmente en el verano, período de predominio del virus. Según la Organización Mundial de la Salud (OMS), el dengue es una patología febril asociada a dos o más de los síntomas: cefalea,

${ }^{1}$ Instituto Metropolitano de Ensino Superior (IMES UNIVAÇO), Ipatinga - MG.

*E-mail: pedroduarte08@hotmail.com

SUBMETIDO EM: 7/2021

ACEITO EM: 7/2021

PUBLICADO EM: $8 / 2021$

REAC | Vol. 33 | DOI: https://doi.org/10.25248/REAC.e8475.2021 
dolor retroorbitario, mialgia / artralgia, exantema y petequias de asa positiva, de inicio agudo que dura 2-7 días. El GBS, por otro lado, es una polirradiculoneuropatía inflamatoria desmielinizante aguda de naturaleza autoinmune, es decir, el sistema inmunológico reconoce y ataca al sistema nervioso, lo que daña la vaina de mielina. Consideraciones finales: Por lo tanto, este estudio reveló una asociación entre el SGB y este arbovirus, siendo la fiebre el síntoma principal para identificar la infección por arbovirus, seguida de mialgias, artralgias y exantema, así como paresias y / o plegias progresivas y ascendentes. la identificación de GBS. Así, la prevención frente a vectores es fundamental para reducir la tasa de infecciones y, en consecuencia, reducir los casos de posible desarrollo de SGB, mejorando el pronóstico de los pacientes.

Palabras clave: Síndrome de Guillain-Barré, Dengue, Complicaciones.

\section{INTRODUÇÃO}

As arboviroses são consideradas um dos principais problemas de saúde no mundo, sendo que, a Organização Mundial da Saúde (OMS) afirma que 80 milhões de pessoas se infectam anualmente, em mais de 100 países, de todos os continentes, exceto pela Europa. Destes, 550 mil necessitam de hospitalização, e 20 mil já morrem em consequência das arboviroses, principalmente a Dengue. O Aedes aegypti, mosquito transmissor da dengue é de origem africana e vem se espalhando pelas regiões tropicais há 5 séculos, sendo datada do período das navegações europeias (INSTITUTO OSWALDO CRUZ, 2020).

A doença foi descrita pela primeira vez em 1762, tendo sua propagação acentuada no período colonial no continente americano devido ao tráfico de escravos, principalmente da África para as Américas. A primeira grande epidemia de dengue no continente ocorreu no Peru, no início do século 19, tendo, posteriormente, surtos em outras regiões da América do Sul, Caribe e América do Norte (CAMARA TN, 2016).

No Brasil, os primeiros relatos de dengue foram no final do século XIX em duas localidades, a primeira em Curitiba e anos após em Niterói. Em 1955, o país eliminou o mosquito Aedes aegypti devido a medidas para controle de uma outra arbovirose, a febre amarela. Entretanto, poucos anos depois, com o relaxamento da população com as medidas adotadas, houve a reintrodução do vetor no país, o qual é mais evidente nos meses chuvosos (WILLISON W, et al., 2016).

Atualmente esse mosquito, que também é o vetor de doenças como Chikungunya e Zika, aparece como um dos principais desafios para as autoridades sanitárias brasileiras, visto que é a arbovirose mais prevalente no território brasileiro, podendo originar diversas complicações nos pacientes, inclusive levar ao óbito subitamente (CAMARA TN, 2016).

A dengue é uma síndrome infecciosa febril aguda que pode ser transmitida por duas espécies de mosquitos, o Aedes aegypti e o Aedes albopictus (WILLISON W, et al., 2016). Existem cerca de cinco sorotipos conhecidos do complexo Dengue Vírus (DENV): DENV-1, DENV-2, DENV-3, DENV-4 e DENV-5, sendo que nas Américas há o predomínio dos sorotipos 1 a 4, com o DENV 5 predominando no continente asiático (DONALISIO M, et al., 2017).

A doença é endêmica em vários países tropicais e subtropicais, especialmente no sudeste da Ásia, bacia do Caribe, América do Sul e ilhas do Pacífico. Sendo assim, tornou-se uma das principais arboviroses mais comuns em todo o mundo, principalmente devido ao fato de ser o único arbovírus que é totalmente adaptado ao hospedeiro humano e ao ambiente, além do fato de ser a segunda causa de infecção nos viajantes (WILLISON W, et al., 2016).

O ciclo de vida do Aedes aegypti completa-se em torno de 30 a 35 dias, podendo variar a depender das condições do ambiente, sendo que, em média, o ovo do mosquito demora cerca de $48 \mathrm{~h}$ para eclodir quando em contato com água, mas em condições adversas, em que não haja água e com baixa umidade, condições encontradas no inverno, o ovo pode se manter em estado de latência por até 450 dias (TEICH V, et al., 2017).

Portanto, no momento em que as chuvas começam, principalmente no verão, uma população de ovos do mosquito Aedes aegypti já existe e então, o mosquito se restabelece rapidamente com altos índices de infestação e proliferação. No contexto epidemiológico brasileiro atual, as arboviroses com maior circulação 
são Dengue, Chikunguya (CHIKV) e Zika (ZIKV), além do vírus da febre amarela e de outros com potencial de disseminação no país (LOPES N, et al., 2014).

Após a infecção com o vírus da dengue, além das complicações básicas que podem ocorrer, como febre, mialgias e artralgias, podem-se desenvolver várias manifestações neurológicas como: encefalite, mielite, mononeuropatias, encefalomielite disseminada aguda e a Síndrome de Guillain-Barré (SGB). Em regiões com aumento do número de casos ocasionados por esse vírus, a infecção pode ser oligossintomática ou assintomática dificultando ainda mais o diagnóstico neurológico associado a infecção por dengue (LOPES N, et al., 2014).

A prevalência das manifestações neurológicas em tal caso varia de 0,5 a 21\%, no entanto, as complicações de sistema nervoso periférico são responsáveis por aproximadamente $5 \%$ dos casos, sendo de ocorrência mais tardia quando comparadas as desordens do sistema nervoso central (MEHTA M, et al., 2018).

A SGB é uma polirradiculoneuropatia inflamatória desmielinizante aguda de caráter autoimune, em que o próprio sistema imunológico reconhece o sistema nervoso como um antígeno, dessa maneira, acaba atacando-o, levando à lesão da bainha de mielina (VAN DEN BERG B, et al., 2014). É caracterizada por rápida evolução ocasionando perda sensorial, paresia e/ou plegia de membros que quase sempre é simétrica e hipo ou arreflexia. As principais causas da doença são reações prévias a infecções causadas por vírus e bactérias (ATKINSON S, et al., 2016).

As infecções causadas por bactérias e vírus, como Campilobacter jejuni, citomegalovírus, vírus Epstein Barr, dengue, vírus da imunodeficiência humana (HIV) e outras infecções virais, como as hepatites virais estão diretamente relacionadas à SGB (WILLISON W, et al., 2016). A SGB tornou-se a causa mais frequente de fraqueza flácida aguda ou subaguda em todo o mundo, afetando ligeiramente mais homens do que as mulheres (WILLISON W, et al., 2016).

Com o surgimento das terapias imunomoduladoras, a imunoglobulinas intravenosas (IVIG) e o Plasma Exchange (PE), o prognóstico da SGB melhorou progressivamente, tornando-se mais acessível à população. No entanto, em pacientes que estão em ventilação mecânica (VM), ainda se tem um pior prognóstico e uma maior taxa de sequelas e complicações (ATKINSON S, et al., 2016).

Considerando estes aspectos, o presente estudo teve como objetivo correlacionar a infecção pela principal arbovirose brasileira com o desenvolvimento da SGB.

\section{REVISÃO BIBLIOGRÁFICA}

De acordo com a OMS, a dengue é uma patologia febril associada a dois ou mais dos sintomas: cefaléia, dor retroorbital, mialgia/ artralgia, exantema e petéquias com prova do laço positiva, de início agudo com duração de 2-7 dias. Apresentações hemorrágicas são menos comuns e a mialgia é observada em aproximadamente $93 \%$ dos pacientes acometido com dengue, sendo caracterizada por dor, sensibilidade e edema muscular leve associado ao aumento de Creatinofosfoquinase (CPK) (PUCCIONI S, et al., 2014).

O vírus da dengue, que pertence ao gênero Flavivirus, é transmitido pelo mosquito Aedes aegypti que ao picar o ser humano, inocula o vírus no homem, originando a infecção viral. É uma doença prevalente em mais de 100 países, amplamente distribuída nos de clima tropical, além de ser responsável por 390 milhões de infecções por ano, sendo 96 milhões com manifestações clínicas que, em muitas das vezes, necessitam de intervenções médicas (WORLD HEALTH ORGANIZATION (WHO), 2020).

De acordo com dados do Ministério da Saúde, no Brasil, em 2020, mais de 928 mil casos de dengue foram notificados, com incidência de 441,7 casos por 100 mil habitantes. Nesse período, a maior incidência foi detida pela região Centro-Oeste, com 1.078,3 casos por 100 mil habitantes, seguida das regiões Sul (923,6 casos $/ 100$ mil habitantes), Sudeste (333,4 casos/100 mil habitantes), Nordeste (189,4 casos/100 mil habitantes) e Norte (101,8 casos/100 mil habitantes). Além disso, os estados do Acre, Bahia, São Paulo, Paraná, Mato Grosso do Sul, Mato Grosso, Goiás e Distrito Federal destacam-se com incidências acima da incidência encontrada no Brasil (BRASIL, 2020; WHO, 2020). 
Além disso, é bem estabelecida a associação da SBG com infecções agudas prévias, sendo observada em cerca de $60 \%$ a $70 \%$ dos pacientes (BRASIL, 2015). Muitos sintomas neurológicos como amnésia, demência, psicose, síndrome de Reye, meningoencefalite e especialmente a SGB são observados em pacientes que tiveram infecção recente por dengue (GARG RK, et al., 2015). Pelo fato de o vírus da dengue raramente afetar o Sistema Nervoso Central (SNC), complicações neurológicas após infecção por esse vírus são menos comuns, no entanto, podem acontecer e originar complicações graves, piorando o prognóstico do paciente (GARG RK, et al., 2015).

A etiopatogenia da SGB após a infecção por dengue ainda não está completamente esclarecida, porém acredita-se que o mimetismo molecular, o qual desenvolve um ataque imune sobre a bainha de mielina e sobre os axônios, e citocinas pró-inflamatórias, como fator de necrose tumoral (TNF), estão diretamente relacionados a esses mecanismos (SOYSAL A, et al., 2014).

A Infecção do SNC tem sido confirmada por meio de identificação de anticorpos contra a dengue, Imunoglobulina M (IgM) - sorologia, vírus RNA por meio de reação de cadeia de polimerase (PCR) e isolamento viral, principalmente em pacientes com sinais e sintomas neurológicos (GOURINAT AC, et al., 2015). Durante a infecção aguda, o vírus pode ser identificado pelo PCR e pelo isolamento viral até o $5^{\circ}$ dia de infecção, já os anticorpos IgM podem ser identificados na corrente sanguínea do paciente a partir do $6^{\circ}$ dia de infecção até 3 meses do início dos sintomas pelos exames de sorologia (GOURINAT AC, et al., 2015). Os anticorpos Imunoglobulina G ( $\mathrm{lgG}$ ) apresentam baixos no princípio dos sintomas, aumentando-se lentamente ao final da primeira semana de doença.

Em contrapartida, em uma infecção secundária, altos níveis de IgG são detectáveis com a IgM podendo ficar negativa (CHAVES MRO, et al., 2016). Uma pessoa pode se infectar por vários sorotipos da dengue, sendo que nas próximas infecções, a gravidade e o comprometimento clínico vai piorando, haja visto que os anticorpos de memória da primeira infecção imuno facilitam a entrada de outros sorotipos, propiciando uma maior entrada viral no organismo que gera uma resposta imune exacerbada, que por sua vez piora a sintomatologia, visto que os sintomas do indivíduo advém dessa resposta imune e não do vírus propriamente dito (CHAVES MRO, et al., 2016).

A técnica de PCR é considerada o método mais sensível para identificação do vírus, no entanto, por detectar a carga viral, necessita de ser realizada durante o período de viremia, que vai até o $5^{\circ}$ de infecção e após esse período, é preferido o exame de sorologia, a partir da pesquisa de $\operatorname{lgM}$ e $\lg G$ no plasma sanguíneo (LI G, et al., 2017). Já no Líquido Cefalorraquidiano (LCR), a identificação da dengue IgM por meio da técnica ELISA tem alta especificidade, porém possui uma sensibilidade variável a depender do método utilizado. É importante ressaltar que o marcador IgG não é utilizado, visto que ele se positiva diante de infecção prévia permanecendo positivo por toda a vida e, diferentemente do $\operatorname{lgM}$, pode ultrapassar a barreira hematoencefálica (GARC RK, 2017).

Portanto, apesar da identificação de um marcador sorológico ser capaz de identificar a infecção, sua ausência não exclui o diagnóstico de dengue na presença de manifestações clínicas sugestivas da arbovirose (GARC RK, 2017). Em um estudo brasileiro realizado por Jugpal TS (2017), foi relatado que a Ressonância Nuclear Magnética (RNM) em comparação com a Tomografia Computadorizada (TC) de crânio é mais sensível e eficaz para detecção de anormalidades encefálicas, sendo as alterações mais comuns presentes nos núcleos da base, tálamo, córtex cerebral, cerebelo e substância branca.

Em relação ao quadro clínico da SGB, frequentemente, o sintoma mais percebido pelos pacientes é a paresia de padrão progressivo e ascendente e a maioria dos pacientes apresenta-se com tetraparesia ou com paresia de membros inferiores. (SUDULAGUNTA SR, et al, 2015). Todos os pacientes com infecção prévia de dengue evoluíram com tetraparesia, o que representou $84,2 \%$ dos casos. A presença de reflexos profundos diminuídos ou abolidos também é um achado clínico importante para a suspeita e diagnóstico da SGB, sendo o nervo facial (XIIo par craniano) o mais acometimento na síndrome. Sua paresia ocorre em metade dos pacientes ao longo do curso da doença, sendo mais comum o acometimento bilateral (SUDULAGUNTA SR, et al., 2015). 
O diagnóstico da SGB é primariamente clínico, entretanto, alguns exames complementares são necessários para sustentar a suspeita clínica, bem como para excluir outras possíveis causas de paresia flácida aguda. Lança-se mão, portanto, de dois artifícios complementares: a análise do LCR e o exame eletroneurofisiológico (BOO Y L, et al., 2019). Para ser considerada SGB a concentração de proteína no LCR deve ser maior que $45 \mathrm{mg} / \mathrm{dL}$, ter a presença de menos de 10 células $/ \mathrm{mm} 3$, além de uma alteração no exame eletroneurofisiológicos (BRASIL, 2015).

Os exames de neuroimagem, tais como a tomografia computadorizada ou a ressonância magnética não fazem parte do rol de exames complementares necessários para o diagnóstico da SGB. Entretanto, eles servem para excluir determinados diagnósticos e foram realizados em alguns pacientes (BRASIL, 2017). O período entre a infecção e o desenvolvimento dos primeiros sintomas da SGB, após a infecção por alguma doença viral febril aguda, no caso a dengue, varia de sete dias a quatro semanas (HUGHES R A, et al., 2015).

Segundo descrito pelo Brasil (2017), a febre é o principal sintoma para a identificação da infecção pelo arbovírus, seguido de mialgia, artralgia e exantema, bem como paresias e/ou plegias progressivas e ascendentes são fatores determinantes para a identificação da SGB. Esses sintomas são comuns, o que dificulta a identificação apenas com os sinais clínicos, sendo necessário a coleta de amostras dos pacientes suspeitos (BRASIL, 2017).

Em geral, o prognóstico da SGB devido à infecção por arboviroses é favorável com aproximadamente $90 \%$ dos pacientes recuperando completamente a força muscular em um ano após o início dos sintomas neurológicos (SOYSAL A, et al., 2014). A taxa de mortalidade varia, mas geralmente é devido a consequência de insuficiência respiratória, arritmias cardíacas, infecções hospitalares e embolia pulmonar (HUGHES RA, et al., 2015).

O tratamento específico da SGB inclui o uso de plasmaférese, imunoglobulina humana intravenosa (IgIV) e a fisioterapia motora que deve ser iniciada com intuito de auxiliar na mobilização precoce do paciente (RAPHAEL JC, et al., 2018). A plasmaférese realiza a separação do plasma e das células sanguíneas, o que auxilia na remoção de anticorpos e de fatores relacionados à formação de lesões no sistema nervoso na SGB (RAPHAEL JC, et al., 2018). Ela aumenta a probabilidade dos pacientes deambularem de forma independente em 4 semanas, e a cada sessão de plasmaférese há remoção de uma volemia de plasma, com intervalo de 48 horas entre sessões. Pacientes que não conseguem ficar em pé sem auxílio devem receber quatro sessões enquanto pacientes com envolvimento leve podem se beneficiar de duas sessões (CHEVRET S, et al., 2017).

A IgIV, pela facilidade de uso, tornou-se o tratamento de escolha na maioria dos países, apesar de seu mecanismo de ação pouco compreendido, no entanto, sua eficácia na recuperação motora, risco de morte e efeitos adversos comparada ao tratamento com plasmaférese mostrou que os resultados dentro de duas semanas são semelhantes (HUGHES RA, et al., 2015). A dose recomendada de IgIV na SGB é de $2 \mathrm{~g} / \mathrm{Kg}$ dividida em 2 a 5 dias, sendo os glicocorticoides contraindicados no tratamento da SGB, assim como poliglicosídeo e a a filtragem do líquor (KORINTHENBERG R, et al., 2015).

O encaminhamento ágil para o atendimento especializado e a identificação precoce de fatores de risco e da doença, dão à Atenção Básica um papel essencial para um melhor resultado clínico, terapêutico e prognóstico dos pacientes (RAPHAEL JC, et al., 2018).

\section{CONSIDERAÇÕES FINAIS}

O estudo evidenciou e confirmou o objetivo levantado no início do artigo, haja vista que foi observado uma ampla associação entre a infecção pelo vírus da dengue e o desenvolvimento da Síndrome de Guillain-Barré, sendo a paralisia de membros o principal indicativo para diagnóstico e a febre, para a suspeita da infecção. Dessa maneira, este artigo é de suma importância, visto que a arbovirose em questão possui altas taxas de infecção e pode gerar inúmeras complicações, assim é imprescindível a conscientização da população por meio de ações sociais, como campanhas educativas, para a prevenção contra o vetor dessa arbovirose, a fim de diminuir o índice de infecções, consequentemente diminuindo os casos de possível desenvolvimento da SGB e de outras síndromes neurológicas. 


\section{REFERÊNCIAS}

1. ATKINSON S, et al. The challenges of managing and treating Guillain-Barré syndrome during the acute phase. Nat Rev Neurol, 2016; 25: 256-63.

2. BOO Y, et al. Síndrome de Guillain-Barré complicando a dengue: relato de dois casos. Tzu Chi Medical Journal, 2016; 28: 157-159.

3. BRASIL. Ministério da Saúde: Secretaria de Atenção à Saúde. 2015. Disponível em: https://portalarquivos2.saude.gov.br/images/pdf/2015/novembro/20/MINUTA-de-Portaria-SAS-PCDT-Guilain-Barr--ATUALIZADO-11-11-2015.pdf. Acessado em 8 de julho de 2021.

4. BRASIL. Ministério da Saúde: Secretaria de Vigilância em Saúde. 2017. Disponível em: https://bvsms.saude.gov.br/bvs/publicacoes/manual_vigilancia_sentinela_doencas_arbovirus.pdf. Acessado em: 8 de julho de 2021

5. BRASIL. Ministérios de Saúde. 2020. Disponível em http://plataforma.saude.gov.br/anomalias-congenitas/boletimepidemiologico-SVS-28-2020.pdf. Acessado em: 8 de junho de 2021.

6. BRASIL. Laboratório Central de Saúde Pública (LACEN/GO). 2017. Disponível em: https://www.saude.go.gov.br/files/lacen/manual-diagnostico-das-arboviroses-go.pdf. Acesso em: 8 julho de 2021.

7. CAMARA TN. Arboviroses emergentes e novos desafios para a saúde pública no Brasil. Revista de Saúde Pública, 2016; 50.

8. CHAVES MRO, et al. Dengue, Chikungunya e Zika: a nova realidade brasileira. Newslab- revista digital, 2016 ; 132 : 137-150.

9. CHEVRET S, et al. Plasma exchange for Guillain-Barre syndrome. Cochrane Database Syst Rev, 2017; 27: 1-2

10. DONALISIO M, et al. Arboviruses emerging in Brazil: challenges for clinic and implications for public health. Revista de Saúde Pública, 2016; 51: 1-6.

11. GARG RK, MALHOTRA HS. Dengue associated neuromuscular complications. Neurol India, 2015; 63: 497-516.

12. GARG RK, MALHOTRA HS. Dengue encephalopathy: very unsual neuroimaging findings. J Neurovirol, 2017; 23: 779-782.

13. GOURINAT A, et al. Detection of Zika virus in urine. Emerging infectious diseases, 2015; 21: 84-86.

14. HUGHES R, et al. Cuidados de suporte para pacientes com síndrome de Guillain-Barré. Arch Neurol, $2015 ; 65: 194-$ 1198.

15. INSTITUTO OSWALDO CRUZ (IOC). Dengue: vírus e vetor. 2020. Disponível em: http://www.ioc.fiocruz.br/dengue/textos/longatraje.html. Acessado em: 29 de julho de 2021.

16. JUGPAL TS, et al. Spectrum of findings on magnetic resonance imaging of the brain in patients with neurological manifestations of dengue fever. Radiol Bras, 2017; 50: 285-90.

17. KORINTHENBERG R, et al. Intravenously administered immunoglobulin in the treatment of childhood guillain-barré syndrome: a randomized trial. Pediatrics, 2015; 116: 8-14

18. LI G, et al. Neurological Manifestations of Dengue Infection. Front. Cell. Infect. Microbiol, 2017; 7: 449.

19. LINDENBACH B, et al. Flaviviridae: the viruses and their replication. Fields virology, 2017; 5: 1101-52.

20. LOPES N, et al. Características gerais e epidemiologia dos arbovírus emergentes no Brasil. Revista Pan-Amazônica de Saúde, 2014; 3: 55-64.

21. MEHTA M, et al. An uncommon complication of Dengue. J stoke Cerebrovasc, 2018; 27: 46-7.

22. OEHLER E, et al. Infecção pelo vírus Zika complicada pela síndrome de Guillain-Barré - relato de caso. Jornal europeu sobre vigilância de doenças infecciosas, epidemiologia, prevenção e controle, $2014 ; 1$.

23. PUCCIONI-SOHLER M, et al. Neurological complications in dengue infection: a review for clinical practice. Arq. Neuropsiquiatr, 2014; 71: 667-71.

24. RAPHAEL JC, et al. Plasma exchange for Guillain-Barre syndrome. Cochrane Database Syst Rev, 2018

25. SOYSAL A, et al. Clinico-electrophysiological findings and prognosis of Guillain-Barré syndrome--10 years experience. Acta Neurol Scand, 2014; 123: 181-186.

26. SUDULAGUNTA S, et al. Guillain-Barré syndrome: clinical profile and management. German Medical Science, 2015; 13: $1-15$.

27. TEICH V, et al. Aedes aegypti e sociedade: o impacto econômico das arboviroses no Brasil. Jornal Brasileiro de Economia da Saúde, 2017; 9: 267-276.

28. VAN DEN BERG B, et al. Guillain-Barré syndrome: pathogenesis, diagnosis, treatment and prognosis. Nat Rev Neurol, 2014; 10: 469-82.

29. WORLD HEALTH ORGANIZATION (WHO). Dengue and severe dengue. 2021. Disponível em: https://www.who.int/news-room/fact-sheets/detail/dengue-and-severe-dengue. Acessado em: 08 de julho de 2021

30. WILLISON H, et al. Guillain-Barré syndrome. The Lancet, 2016; 388: 717-727. 